\title{
Characteristics associated with the application of an ecological approach to preventing childhood obesity
}

\author{
Christina M Stark* , Carol M Devine and Jamie S Dollahite \\ Division of Nutritional Sciences, Savage Hall, Cornell University, Ithaca, NY 14853, USA
}

Submitted 18 December 2015: Final revision received 18 May 2016: Accepted 7 June 2016: First published online 13 July 2016

\begin{abstract}
Objective: Applying an ecological approach to childhood obesity prevention requires a new way of thinking and working for many community-based practitioners who are used to focusing on individual behaviour change. The present study investigated individual and organizational characteristics associated with the application of an ecological approach by practitioners 6 months post-training.

Design: Individual and organizational characteristics and outcomes of a 6-week online training course were assessed at pre-course, post-course and 6-month follow-up. The application of an ecological approach was measured by three outcomes (application of course content, implementation of an action plan and trying a different approach) and analysed using a generalized estimating equation model with a binomial distribution and logit link and linear mixed models.

Setting: An online course for participants in the USA and abroad.

Subjects: Public health nutrition and youth development educators and their community partners, and other community practitioners, who completed the course and all three surveys ( $n$ 240).

Results: One individual characteristic (networking utility) and three organizational characteristics (ecological approach within job scope, funding, course content applied to work) were positively and significantly associated with the application of an ecological approach $(P<0.05)$. Individual characteristics that were negatively and significantly associated with the application of an ecological approach were being a registered dietitian and having $\geq 16$ years of work experience $(P<0 \cdot 05)$.

Conclusions: Training of community practitioners and the scope and funding of their positions should explicitly emphasize the usefulness or utility of networking and the use of an ecological approach for preventing childhood obesity.
\end{abstract}

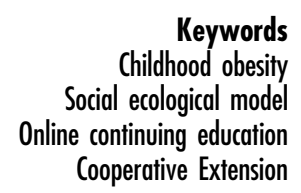

Keywords

Social ecological model

Cooperative Extension
Childhood obesity continues to be a major public health problem, with an estimated $32 \%$ of children and adolescents in the USA either overweight or obese ${ }^{(1)}$. While the prevalence is lower in most other countries, infant, child and adolescent obesity is rising at alarming rates around the world $^{(2)}$. New approaches are urgently needed to improve the health of this generation and the next ${ }^{(2,3)}$.

Many community-based nutrition and health practitioners have been trained to promote healthy eating using direct nutrition education focused on individual behaviour change. This approach alone has not been effective for addressing obesity and upstream approaches that emphasize change at individual, family and community levels have received increased support ${ }^{(3-6)}$. A social ecological model describes the multiple levels of influence on an individual's behaviour including food and activity choices and ultimately on children's weight status ${ }^{(4,7,8)}$. The model illustrates how an individual's food and activity choices are not only influenced by personal factors (examples: age, gender, knowledge, skills) but also by the various environmental settings (home, school), sectors of influence (government, public health system, agriculture) and social norms (heritage, lifestyle) that interact and surround an individual $^{(8)}$. In other words, children make food choices within the context of their family, school, community and cultural belief systems. Community-based, multilevel interventions that use an ecological approach, combining direct education with policy, systems and environmental changes, are considered more effective strategies for obesity prevention in both children and adults ${ }^{(3,8-11)}$.

Public health training has long recognized the importance of community-focused, population-based interventions; 


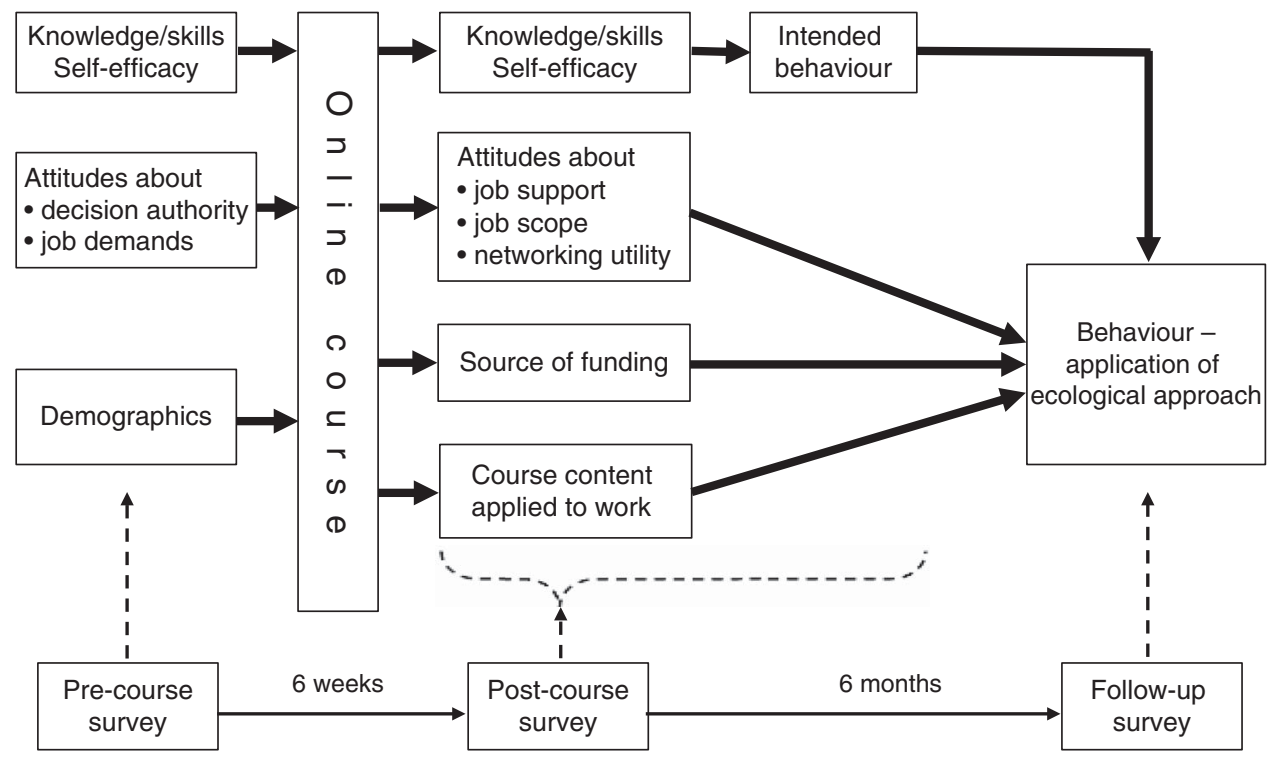

Fig. 1 Conceptual model used to determine associations between individual and organizational characteristics and the application of an ecological approach

however, for professionals trained to focus on individual behaviour change, applying an ecological approach to childhood obesity prevention at the community level requires a new way of thinking and working ${ }^{(12-16)}$. To build the capacity of professionals in using an ecological approach, an online course, Preventing Childhood Obesity: An Ecological Approach, was developed by faculty in the Division of Nutritional Sciences at Cornell University. Previous research results showed the course was effective at increasing the knowledge, skills and self-efficacy of professionals in using an ecological approach immediately post-course ${ }^{(16)}$.

The aims of the current study were to measure the extent to which an ecological approach was applied at the community level 6 months post-course, and what individual and organizational characteristics were associated with a participant's likelihood of applying an ecological approach. Figure 1 shows the conceptual model used for the study.

\section{Methods}

\section{Course participants}

Participants in the current study came from the pool of community practitioners, including those in public health nutrition and youth development, who had voluntarily enrolled in and completed the 6-week-long online training, Preventing Childhood Obesity: An Ecological Approach. The content for this 6-week course was designed around the PRECEDE-PROCEED health programme planning model ${ }^{(17)}$, which involves identifying and prioritizing underlying factors contributing to a health problem in order to strategically develop an intervention. In this course childhood obesity was the predefined health problem and participants were guided through the steps of the planning process to develop an action plan for intervention customized to their local setting ${ }^{(16)}$. The course required participants to submit local obesity prevalence data to a discussion forum, participate in two additional asynchronous discussion forums and submit a four-part course project which became their action plan. To develop their action plan, participants: (i) identified and prioritized behavioural, environmental and other local factors that contributed to excessive child weight gain in their communities (example: sweetened beverages are widely available in the vending machines at schools); (ii) developed objectives to address the priority factors (the availability of sweetened beverages in the vending machines will decrease by $75 \%$ in 2 years); (iii) identified appropriate collaborators needed to address the identified priorities (school wellness team, school principal, parents, students); (iv) identified appropriate intervention methods and strategies (organizational and policy change); (v) identified specific action steps needed to carry out those strategies (create new policy limiting sweetened beverages in school vending machines); and (vi) described an evaluation plan to determine if their objectives had been met (measure availability and sales of sweetened beverages pre- and post-intervention). At course end, participants, either individually or as teams, had developed an action plan describing a collaborative, ecological approach to address childhood obesity tailored to their own communities. Course completers earned fifteen continuing professional education units. Additional details on the course content and format can be found elsewhere ${ }^{(16)}$.

The target audience for the course were teams of at least three people, consisting of a nutrition educator and a 4-H youth development educator, who were both employed 
by Cooperative Extension at the local level, and a community-based partner not employed by Cooperative Extension. Cooperative Extension is a national system that provides non-formal education and learning activities to people throughout the $\mathrm{USA}^{(18)}$. The $4-\mathrm{H}$ programme is a global youth development and mentoring programme that is delivered through Cooperative Extension in the USA. Many nutrition educators in the USA receive specific funding that requires them to focus their educational efforts on low-income families and youths either through the Expanded Food and Nutrition Education Program (EFNEP) ${ }^{(19)}$ or through the Supplemental Nutrition Assistance Program-Education (SNAP-Ed) ${ }^{(20)}$. Requiring target teams to consist of at least two types of Extension educators and a non-Extension community partner was a strategic way to initiate and/or support collaboration at the local level.

Course participants were recruited through messages to electronic listservs that served Extension and public health professionals, as well as with recruitment flyers distributed at professional meetings. Individuals on teams who met the target team criteria were allowed to enrol for a halfprice fee of \$US 75 per person. Extension teams were targeted for priority enrolment; non-Extension teams or other community-based practitioners, in the USA or beyond, were allowed to enrol, either as teams or as individuals, as spaced permitted. Each team or individual was expected to develop an action plan throughout the course and, during its development, each action plan required multiple reviews by a single facilitator. Each course session was limited to twenty-five teams and/or individuals to give the facilitator time for detailed review and response to each of the action plans.

Eight course sessions were delivered between autumn 2010 and spring 2013, and each session was guided by the same facilitator. Everyone who enrolled, whether on a team or not, was individually sent the pre-course and postcourse surveys, but only course completers were sent the 6-month follow-up survey. Course completers were defined as those who had either individually or as a team submitted the four-part course project, which was their tailored action plan. Given the low-risk nature of participation, consent was indicated by the participant submitting the online surveys. This research was reviewed by the Cornell University Institutional Review Board for Human Participants and found to qualify for Exemption from IRB Review (protocol ID\# 0901000009) according to paragraph \#2 of the US Department of Health and Human Services' Code of Federal Regulations 45 CFR 46.101(b).

\section{Measures}

Pre-course, post-course and 6-month follow-up online surveys were used to assess which pre-existing individual and organizational characteristics were related to the three outcomes reflecting the application of an ecological approach: (i) applied what I learned; (ii) implemented action plan; and (iii) tried a different approach. The three surveys were developed by the researchers by expanding surveys used in a previous study ${ }^{(16)}$. For the current study additional validated scales were added to all three surveys to measure specific characteristics that might be associated with the outcomes. For measures related to family demands at home, decision authority, management and co-worker support, and demands at work, items from the National Survey of Midlife Development in the United States (MIDUS) were used ${ }^{(21)}$. For measures related to job scope and funding, items were taken from a study by $\mathrm{Lu}^{(22)}$, and items related to networking were taken from the same study by Lu, as well as the Political Skill Inventory developed by Ferris and colleagues $^{(22,23)}$.

The pre-course survey assessed participants' individual characteristics related to areas of employment, education, years of work experience, age, marital status, the presence of young children at home, their sense of control over time at home, and their pre-course knowledge/skills and selfefficacy related to applying an ecological approach; and organizational characteristics related to their level of decision making on the job (combined into a scale called decision authority) and the level of demands on their time on the job (job demands). The post-course survey assessed individual characteristics related to the usefulness or utility they attributed to networking with others (networking utility) and their post-course knowledge/skills and self-efficacy related to applying an ecological approach; and organizational characteristics related to how much support they had within their jobs for using an ecological approach (job support), whether this type of approach was within the scope of their job (job scope), the sources of funding for their position and if the course content applied directly to their work. Sample questions for each scale included the following: 'How often do you have a choice in deciding how you do your tasks at work?' (decision authority), 'How often do different people or groups at work demand things from you that you think are hard to combine?' (job demands), 'I am good at using my connections and network to make things happen in my job' (networking utility), 'My supervisor supports my use of ecological approaches to address childhood obesity prevention' (job support) and 'Using ecological approaches to address childhood obesity prevention falls within my job scope' (job scope).

Dependent variables were the three outcomes assessed at the 6-month follow-up: 'I have applied what I learned in this course to my work' ('yes'/"no'); 'To what extent have you implemented some or all of an action plan for addressing childhood obesity in your community?' (fivepoint scale ranging from 'not at all' to 'a lot'); and 'To what extent did this course help you try a different approach to addressing childhood obesity in your community?' (same five-point scale). 


\section{Data analysis}

For the current study we hypothesized that participants would be more likely to apply an ecological approach 6 months post-course if they had:

1. stated immediately post-course that they intended to apply an ecological approach;

2. individual characteristics including more years of education, fewer years of work experience, fewer family demands on their time, higher utility of networking, and higher pre- or post-course knowledge/skills and self-efficacy about applying an ecological approach;

3. organizational characteristics including support for using an ecological approach from supervisors or coworkers, using an ecological approach within their job scope, more decision authority, higher control over their work time, the content applied directly to their work, and EFNEP or SNAP-Ed funding; and

4. enrolled in the course as a team.

Sample size calculations determined that a sample size of sixty-five per group was needed to determine a significant effect size of 0.7 for two outcome variables, implemented action plan and tried a different approach, with $80 \%$ power and $P \leq 0.05$ for a two-sided test. The final sample of 240 supported analysis of the proportions of those who applied what they learned in the course with a total width of the $95 \%$ CI equal to $10 \%$.

A differential attrition analysis was done to determine if the demographics or funding source of those who completed the three surveys differed from those who completed at least one, but not all three surveys. The remaining data analyses were done on the survey results only from those with three matched surveys.

The $\chi^{2}$ test of independence was used to examine the relationship between the responses related to questions about intention on the post-course survey and the responses to the corresponding questions about action on the 6-month post-course survey.

Internal reliability was assessed for the five scales, with the number of items and the resulting Cronbach's $\alpha$ coefficients as follows: networking utility (six items, 0.903), decision authority (six items, 0.812), job demands (five items, 0.746), job support (four items, 0.796) and job scope (three items, 0-800). The resulting Cronbach's $\alpha$ coefficients indicate high internal reliability of the scales.

Bivariate analyses (cross-tabulations with $\chi^{2}$ tests of independence, comparison of means with $t$ tests and ANOVA, and simple regressions) were conducted between each of the three outcomes and individual characteristics, the five scales, the source of funding, preand post-course knowledge/skills, pre- and post-course self-efficacy and team enrolment.

To further analyse the dependent variable 'I have applied what I learned in this course to my work', a generalized estimating equation (GEE) model with a binomial distribution and a logit link was used. To analyse the other two dependent variables, 'To what extent have you implemented some or all of an action plan?' and 'To what extent did this course help you to try a different approach?', linear mixed models were used. These two models were used to control for clustering of the subjects in sessions. Covariates considered in the models were the same ones used in the bivariate analyses. The final GEE and linear mixed models retained all five scales and any other independent variables that were significant for at least one of the dependent variables. All data analyses were conducted using the statistical software package IBM SPSS Statistics Version 22.0. The level for determining statistical significance was $P \leq 0.05$ for all comparisons.

\section{Results}

A total of 383 people enrolled in the course in one of the eight identical sessions. Of these, the vast majority (355) were from forty-three states in the USA. Although recruitment efforts did not target community practitioners in other counties, twenty-eight people from ten other countries enrolled. Overall, 246 individual people were enrolled as members of seventy-five Extension target teams (consisting of at least one Extension nutrition educator, one Extension 4-H youth development educator and one community-based partner not employed by Extension), sixty-nine enrolled as members of thirty-two other (nonExtension) teams (two to five people who worked in the same community and enrolled in the course as a team, but who did not meet the definition of a target team) and sixtyeight enrolled as individuals. The pool of potential study participants included not only those who had enrolled on target Extension teams, but also those who enrolled on other teams or as individuals. Overall, $86 \%$ of those who enrolled completed the course, defined as completing seven separate assignments: the four parts of the course project and the three required discussion forum postings. Enrollees who were on teams had a statistically higher $(P=0.003)$ course completion rate $(88 \%)$ than those who were not on teams $(75 \%)$.

Survey completion, which was voluntary, was a different task from course completion and only course completers had the potential to complete all three surveys. Of total course enrollees, $95 \%$ completed at least one of the three surveys and $63 \%$ completed all three surveys as shown in Fig. 2.

Participant demographics are shown in Table 1. Those who completed all three surveys ( $n$ 240) were not different on most characteristics measured from those who did not ( $n$ 123). The only exception was that completers of three surveys were significantly less likely to be registered dietitians $(P=0 \cdot 046)$.

On the immediate post-course survey, $96 \%$ of the study participants agreed or strongly agreed that they intended 


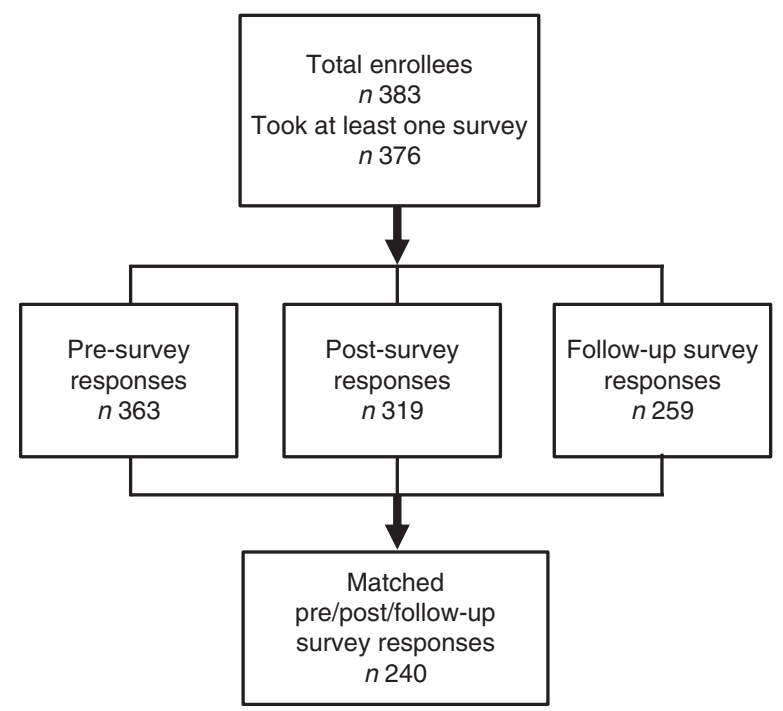

Fig. 2 Number of participants who enrolled over eight sessions of the online course and number who took the pre-survey, post-survey and/or follow-up survey

Table 1 Demographics of online course participants who completed all three surveys ( $n$ 240)

\begin{tabular}{lrr}
\hline & $n$ & $\%$ \\
\hline Employment & & \\
$\quad$ Cooperative Extension (nutrition/family \& & 127 & 53 \\
$\quad$ consumer science/youth development) & & \\
Other (e.g. public health, hospital/clinical, & 113 & 47 \\
$\quad$ college/university, self-employed/consultant & & \\
$\quad$ and other non-specified) & & \\
Education & 138 & 58 \\
$\quad$ Masters or PhD & 97 & 42 \\
$\quad$ Other or missing $(n$ 2) & & \\
Credential (more than one answer possible) & 33 & 14 \\
$\quad$ Registered dietitian & 207 & 86 \\
$\quad$ Other or none ( $n$ 115) & & \\
Work experience (years) & 81 & 34 \\
$\quad \leq 5$ & 77 & 32 \\
$6-15$ & 81 & 34 \\
$\quad \geq 16$ & & \\
Age (years) & 35 & 25 \\
$\quad \leq 29$ & 65 & 27 \\
$30-39$ & 51 & 21 \\
$40-49$ & 71 & 30 \\
$50-59$ & 18 & 8 \\
$\quad \geq 60$ & 170 & 71 \\
Married & 83 & 35 \\
Children <12 years at home & & \\
\hline
\end{tabular}

to apply what they learned in the course to their job and $91 \%$ agreed or strongly agreed they intended to implement at least part of the action plan developed in the course. At the follow-up survey 6 months later, $80 \%$ said they had applied what they had learned and $80 \%$ said they had implemented at least part of an action plan. For these two behaviours, intentions were significantly associated with actions $(P<0.001)$, thus supporting the first study hypothesis.
There was mixed support for the second hypothesis that certain individual characteristics would be positively associated with the application of an ecological approach. The bivariate analyses found three individual characteristics (networking utility, being a registered dietitian and having 16 or more years of work experience) were significantly associated with the application of an ecological approach. But when combined into the GEE and linear mixed models analyses, only one individual characteristic was significantly and positively related to two of the outcomes. As hypothesized, those who had higher scores for networking utility were more likely to have implemented an action plan and more likely to have tried a different approach 6 months post-course. Individual characteristics that were significantly and negatively associated with at least one of the three outcomes were being a registered dietitian and, as expected, having 16 or more years of work experience. Compared with all other credentials, those who were registered dietitians were significantly less likely to have implemented at least some of an action plan, and those with 16 or more years of work experience were significantly less likely to have applied what they learned in the course to their work and significantly less likely to have implemented at least some of an action plan (Table 2).

There was also mixed support for our hypothesis about organizational characteristics. The bivariate analyses found the following organizational or funding factors had a significant and positive association with at least one outcome: job scope, $\geq 50 \%$ EFNEP funding, $\geq 50 \%$ SNAP-Ed funding and if the course content applied to the participant's work. The GEE and linear mixed models found that those with $\geq 50 \%$ EFNEP or $\geq 50 \%$ SNAP-Ed funding were significantly more likely to have applied what they learned in the course to their work. Those with higher job scope scores were significantly more likely to have implemented at least some of an action plan. Lastly, those who strongly agreed or agreed that the knowledge and skills gained in the course applied directly to their jobs were significantly more likely to have applied what they learned to their work and to have tried a different approach (Table 2).

Contrary to our hypothesis, the bivariate analyses revealed that team enrolment was not associated with any of the three outcomes and so this covariate was not included in the final models.

\section{Discussion}

\section{Intentions $\mathrm{v}$. actions}

The Theory of Planned Behaviour suggests that intentions increase the likelihood of an action ${ }^{(24)}$. This theory supports our finding that those who indicated immediately post-course that they intended to apply what they learned in the course or to implement their action plan were significantly more likely to report doing so 6 months later. 
Table 2 Individual and organizational characteristics associated with the three outcomes for applying an ecological approach

\begin{tabular}{|c|c|c|c|c|c|c|c|c|c|}
\hline \multirow{3}{*}{$\begin{array}{l}\text { Individual and organizational } \\
\text { characteristic }\end{array}$} & \multicolumn{9}{|c|}{ Parameter estimates* } \\
\hline & \multicolumn{3}{|c|}{ Applied what I learned† } & \multicolumn{3}{|c|}{ Implemented action plan $\ddagger$} & \multicolumn{3}{|c|}{ Tried a different approach $\ddagger$} \\
\hline & OR & $95 \% \mathrm{Cl}$ & $P$ value & Estimate & SE & $P$ value & Estimate & SE & $P$ value \\
\hline \multicolumn{10}{|l|}{ Credential } \\
\hline Registered dietitian & \multicolumn{3}{|c|}{ Reference } & \multicolumn{3}{|c|}{ Reference } & \multicolumn{3}{|c|}{ Reference } \\
\hline Not registered dietitian & $2 \cdot 55$ & $0.91,7.13$ & 0.074 & 0.39 & $0 \cdot 19$ & 0.041 & 0.06 & 0.22 & 0.766 \\
\hline \multicolumn{10}{|l|}{ Work experience (years) } \\
\hline$\geq 16$ & \multicolumn{3}{|c|}{ Reference } & \multicolumn{3}{|c|}{ Reference } & \multicolumn{3}{|c|}{ Reference } \\
\hline $6-15$ & $6 \cdot 42$ & $2 \cdot 03,20 \cdot 29$ & 0.002 & 0.37 & 0.15 & 0.018 & 0.21 & $0 \cdot 17$ & 0.226 \\
\hline$\leq 5$ & 3.74 & $1.12,12.55$ & 0.032 & 0.32 & 0.17 & 0.056 & 0.29 & 0.19 & 0.124 \\
\hline Networking utility & 1.51 & $0.92,2.47$ & 0.103 & 0.22 & 0.08 & 0.006 & 0.35 & 0.09 & 0.000 \\
\hline Decision authority & 1.07 & $0.52,2.17$ & 0.858 & 0.18 & 0.12 & 0.129 & 0.21 & 0.13 & 0.120 \\
\hline Job demands & 0.52 & $0.26,1.01$ & 0.054 & -0.02 & $0 \cdot 11$ & 0.841 & -0.04 & 0.13 & 0.757 \\
\hline Job support & $1 \cdot 23$ & $0.68,2.23$ & 0.498 & $-0 \cdot 10$ & $0 \cdot 10$ & 0.299 & -0.09 & 0.11 & 0.409 \\
\hline Job scope & 1.36 & $0.86,2.17$ & 0.193 & 0.22 & 0.08 & 0.004 & 0.04 & 0.09 & 0.635 \\
\hline \multicolumn{10}{|l|}{ Funding } \\
\hline$\geq 50 \%$ EFNEP & \multirow{2}{*}{\multicolumn{3}{|c|}{$\begin{array}{l}\text { Reference } \\
\S \\
\text { Reference }\end{array}$}} & \multicolumn{3}{|c|}{ Reference } & \multicolumn{3}{|c|}{ Reference } \\
\hline $\begin{array}{l}<50 \% \text { EFNEP } \\
\geq 50 \% \text { SNAP-Ed }\end{array}$ & & & & $0 \cdot 16$ & $\begin{array}{l}0.42 \\
\text { ference }\end{array}$ & $0 \cdot 703$ & -0.69 & $\begin{array}{l}0.47 \\
\text { ference }\end{array}$ & $0 \cdot 141$ \\
\hline$<50 \%$ SNAP-Ed & 0.08 & $0.01,0.45$ & 0.004 & -0.02 & 0.22 & 0.922 & 0.06 & 0.24 & 0.798 \\
\hline $\begin{array}{l}\text { Course knowledge \& skills } \\
\text { apply to my job }\end{array}$ & 3.73 & $1.62,8.58$ & 0.002 & 0.08 & $0 \cdot 12$ & 0.513 & 0.32 & $0 \cdot 14$ & 0.021 \\
\hline
\end{tabular}

EFNEP, Expanded Food and Nutrition Education Program; SNAP-Ed, Supplemental Nutrition Assistance Program-Education.

${ }^{*} \mathrm{~A}$ generalized estimating equation (GEE) model with a binomial distribution and a logit link was used for the outcome 'I have applied what I learned in this course to my work' and linear mixed models for the outcomes 'To what extent have you implemented some or all of an action plan for addressing childhood obesity in your community?' and 'To what extent did this course help you try a different approach to addressing childhood obesity in your community?'.

tResponse categories: 'yes'/'no'.

fResponse categories: 'not at all', 'a little', 'some', 'a fair amount', 'a lot'.

$\S$ Variable omitted due to complete separation of data (i.e. all six participants who received $\geq 50 \%$ EFNEP funding reported applying the course to their work), resulting in maximum likelihood parameters not being possible to estimate.

\section{Characteristics associated with application of an ecological approach}

These results also show that there are some individual and organizational characteristics that may enhance a community practitioner's ability to apply an ecological approach to preventing childhood obesity using community-based interventions. These findings have important implications for initial professional training, in-service education and the kinds of workplace organizational support needed for ecological approaches to take hold in communities. For example, community practitioners who had higher scores related to networking utility may be more eager and willing to collaborate with others, especially when facing multifactorial problems such as obesity that will require people representing different sectors to work together in order for an intervention to be successful ${ }^{(22)}$. This could help explain the finding that this group of practitioners was more likely to have implemented their action plan or tried a different approach. In another study, allied health professionals similarly reported that they viewed the task of translating evidence into practice as being more realistic, less daunting and more acceptable when done as a group rather than as an individual activity ${ }^{(25)}$. Community and public health organizations that foster multidisciplinary approaches through hiring, organizational structure and staff development may be able to build on this advantage.
Those who indicated that this type of work was within their job scope may have been more likely to implement their action plan because they were allowed the time or already felt like this was something they should be doing. This finding is consistent with an earlier qualitative study in which some nutrition and dietetics professionals saw changes in the food and eating environment within their scope of work while others expressed frustration with their inability to cope with challenging food and eating environments $^{(26)}$. This reasoning may also be applicable to those who had the majority of their funding coming from EFNEP or SNAP-Ed, since they were also more likely to apply what they learned in the course. Overall, individuals who have this type of job description and funding might have felt they had more freedom and support for using an ecological approach.

EFNEP and SNAP-Ed are national programmes which are guided by US federal policies and guidance that define how these programmes are to be implemented. Programme strategies allowed or required under these two programmes have changed over the past 5 years. For example, national EFNEP policies previously stated that community educators funded by EFNEP could only engage in direct nutrition education $^{(27)}$; however in 2015 that changed to also allow policy, systems and environmental approaches ${ }^{(19)}$. Similarly, the passage of the Healthy, Hunger-Free Kids Act in 2010 transformed SNAP-Ed from a nutrition education 
programme to one delivering nutrition education and obesity prevention services, with a focus on comprehensive evidence-based strategies delivered through communitybased and public health approaches ${ }^{(28)}$. Prior to the Act, the federal SNAP-Ed guidance emphasized behavioural outcomes and expected state plans to include behaviourally focused, science-based nutrition education interventions, projects or social marketing campaigns ${ }^{(29)}$. In contrast, the 2016 SNAP-Ed guidance expects state plans to incorporate individual or group-based direct nutrition education, health promotion and intervention strategies with at least one of these two other approaches: (i) comprehensive, multilevel interventions at multiple complementary organizational and institutional levels; and/or (ii) community and public health approaches to improve nutrition ${ }^{(20)}$.

During the years this course was delivered (2010-2013), the transition in policies and guidance for these two programmes was taking place. Therefore, many course participants who had major responsibilities for implementing these programmes (i.e. those with $\geq 50 \%$ EFNEP or $\geq 50 \%$ SNAP-Ed funding) would have been working under the 2010 Dietary Guidelines for Americans ${ }^{(30)}$ which identified the socio-ecological model as an important framework for obesity prevention efforts. In addition, the Healthy, Hunger-Free Kids Act of $2010^{(28)}$ explicitly promoted an ecological approach by allowing government-funded nutrition education and obesity prevention programmes to include comprehensive, multilevel interventions and community and public health approaches. These two documents increased the interest of professionals and provided the basis for the use of these approaches that were subsequently incorporated into programme guidance. With new policies and guidance officially in place, it could be expected that even more community practitioners funded by EFNEP or SNAP-Ed will incorporate an ecological approach into their obesity prevention efforts.

It is not surprising that those who reported the knowledge and skills they learned in the course applied directly to their work were more likely to apply what they learned. But an encouraging finding is that this group was also significantly more likely to report they had tried a different approach 6 months after taking the course. They may have felt that prior to the course they were supposed to be doing this type of work, but didn't know how to try these new approaches until they had the knowledge, skills and self-efficacy to do so. This suggests that training in this approach can help those who are required to do this work actually try it.

Previous professional training may be a possible reason why two personal characteristics (being a registered dietitian and having 16 or more years of work experience) were negatively associated with applying an ecological approach. Traditional training for most dietitians has historically focused on individual behaviour change and client counselling, so this group may have felt less able to implement an ecological approach if their previous training focused on working with individuals. Funding and organizational factors may have also had an impact. Practising dietitians have reported that three common barriers to incorporating an evidence-based approach in their work are lack of resources including money, poor organizational culture and lack of team collaboration ${ }^{(31)}$.

Those with 16 or more years of work experience may also have been trained to focus on direct education and individual behaviour change, and had by definition been doing that type of work for close to two decades or more, so the traditional approach was more ingrained. Therefore, it may have been out of their 'comfort level' to apply what they learned or implement their action plan. Other studies have also reported that years of work experience is a negative predictor for knowledge and attitudes about evidence-based practice among nurses and physicians ${ }^{(31)}$. Notably in the current study, while those with the most work experience were less likely to implement their course action plan, they were not significantly less likely to report trying a different approach to obesity prevention compared with those with less work experience.

\section{Strengths}

Study participants represented a broad range of community practitioners working on childhood obesity and suggest ways that people in a variety of roles may be engaged in this effort. The high level of retention through three survey evaluation rounds adds to the confidence in the findings. To the best of the authors' knowledge, the present study is the first to identify some specific characteristics that can be addressed during hiring, preand in-service training, in developing job descriptions and in funding these positions in order to increase the likelihood that community practitioners are able to implement an ecological approach.

\section{Weaknesses}

There may have been a selection effect, in that those who chose to participate in the online course could be expected to have stronger behavioural intentions to use an ecological approach. The study findings may overstate the use of an ecological approach, as those with greater barriers to using such an approach may not have enrolled in the first place.

\section{Implications}

Of all the individual and organizational characteristics that were examined, only a handful were associated with at least one of the three outcome variables, and there were no factors significantly associated with all three. This could be taken as an encouraging sign that taking an ecological approach to obesity prevention can, in theory, be done by a wide range of community professionals who have been trained in a variety of disciplines and is not the purview of a particular group. 
At the same time, agencies that allow or require staff to take this approach need to consider the organizational characteristics and policies that might enhance success. Managers and supervisors should make sure that staff who are expected to work collaboratively with others in the community to bring about policy, systems and environmental changes have that expectation included in position descriptions, and funders should make it clear that this type of work is valued, if not outright required. Supervisors should encourage staff to network across agencies and sectors as a step in increasing the utility of networking and collaborating with others for more successful outcomes.

Policy and guidance documents alone may not be enough to support these changes. There needs to be an organizational culture that prioritizes and supports community-based, collaborative approaches to health promotion. Networking and collaboration are key aspects of using an ecological approach, but much of what practitioners do will depend on the perspectives and behaviours of others ${ }^{(22)}$. Those who have a comfort level in using more traditional approaches, such as direct nutrition education, will need more training and tools to increase their knowledge, skills and self-efficacy in using new approaches ${ }^{(13,15)}$. A recent nationwide survey of 600 professionals funded by EFNEP and/or SNAP-Ed found there is a high need and desire for training in all aspects of policy, systems and environmental approaches, including planning, implementation and evaluation (T Hill and C Stark, unpublished results).

While our results did not identify a particular type of professional who was more likely to use an ecological approach compared with others, those who have had formal public health training that emphasizes collaboration and community-based approaches might find an ecological approach more aligned with the scope of their work than someone who is a registered dietitian, whose training focuses more on individual counselling. In addition, those who have been working less than 16 years might have had more exposure in school and thus more familiarity with and openness to these types of approaches $v$. someone who has been working for 16 or more years.

\section{Conclusion}

Community practitioners who reported that networking had high utility, who had the use of an ecological approach within the scope of their job or who were funded by agencies that support this type of approach were found to be more likely to apply this approach 6 months post-training. Those who received formal education in dietetics or who had been working for at least 16 years were less likely to use an ecological approach. Training of community practitioners and the scope and funding of their positions should explicitly emphasize the usefulness or utility of networking and the use of an ecological approach for bringing about community change in childhood obesity prevention efforts.

\section{Acknowledgements}

Acknowledgements: The authors would like to acknowledge the support of Jason Barry, Statistical Consultant with the Cornell Statistical Consulting Unit, for his help with data analysis. Financial support: This material is based upon work that was supported by the National Institute of Food and Agriculture, US Department of Agriculture (USDA) (award number 2010-85215-20665). USDA had no role in the design, analysis or writing of this article. Conflict of interest: None. Authorship: All authors were responsible for formulating the research questions and designing the study. C.M.S. carried out the study, supervised the data analysis and drafted the manuscript. C. M.D. and J.S.D. provided input into the manuscript. All authors have read and approved the final version. Ethics of buman subject participation: This research was reviewed by the Cornell University Institutional Review Board for Human Participants and found to qualify for Exemption from IRB Review (protocol ID\# 0901000009) according to paragraph \#2 of the US Department of Health and Human Services' Code of Federal Regulations 45 CFR 46.101(b).

\section{References}

1. Ogden CL, Carroll MD, Kit BK et al. (2014) Prevalence of childhood and adult obesity in the United States, 2011-2012. JAMA 311, 806-814.

2. World Health Organization (2016) Report of the Commission on Ending Childhood Obesity. Geneva: WHO; available at http://apps.who.int/iris/bitstream/10665/204176/1/97892415 10066_eng.pdf

3. Institute of Medicine (2012) Accelerating Progress in Obesity Prevention: Solving the Weight of the Nation. Washington, DC: The National Academies Press.

4. Story M, Kaphingst KM, Robinson-O'Brien R et al. (2008) Creating healthy food and eating environments: policy and environmental approaches. Annu Rev Public Health 29, 253-272.

5. Swinburn B, Gill T \& Kumanyika S (2005) Obesity prevention: a proposed framework for translating evidence into action. Obes Rev 6, 23-33.

6. Kumanyika S, Jeffery RW, Morabia A et al. (2002) Obesity prevention: the case for action. Int $J$ Obes Relat Metab Disord 26, 425-436.

7. Ohri-Vachaspati P, DeLia D, DeWeese RS et al. (2015) The relative contribution of layers of the Social Ecological Model to childhood obesity. Public Health Nutr 18, 2055-2066.

8. US Department of Agriculture \& US Department of Health and Human Services (2015) Dietary Guidelines for Americans 2015-2020, 8th ed. Washington, DC: US Government Printing Office; available at http://health.gov/ dietaryguidelines/2015/guidelines

9. Lyn R, Aytur S, Davis TA et al. (2013) Policy, systems, and environmental approaches for obesity prevention: a framework to inform local and state action. J Public Health Manag Pract 19, E-Suppl., S23-S33.

10. World Health Organization (2012) Population-Based Approaches to Childhood Obesity Prevention. Geneva: WHO.

11. Frieden TR, Dietz W \& Collins J (2010) Reducing childhood obesity through policy change: acting now to prevent obesity. Health Aff (Millwood) 29, 357-363. 
12. Lu AH, Dickin K \& Dollahite J (2014) Development and application of a framework to assess community nutritionists' use of environmental strategies to prevent obesity. J Nutr Educ Behav 46, 475-483.

13. Gantner LA \& Olson CM (2012) Evaluation of public health professionals' capacity to implement environmental changes supportive of healthy weight. Eval Program Plann 35, 407-416.

14. Kugelberg S, Jonsdottir S, Faxelid E et al. (2012) Public health nutrition workforce development in seven European countries: constraining and enabling factors. Public Health Nutr 15, 1989-1998.

15. Schwarte L, Samuels SE, Boyle M et al. (2010) Local public health departments in California: changing nutrition and physical activity environments for obesity prevention. J Public Health Manag Pract 16, E17-E28.

16. Stark CM, Graham-Kiefer ML, Devine CM et al. (2011) Online course increases nutrition professionals' knowledge, skills and self-efficacy in using an ecological approach to prevent childhood obesity. J Nutr Educ Behav 43, 316-322.

17. Green LW \& Kreuter MW (2005) Health Program Planning: an Educational and Ecological Approach, 4th ed. New York: McGraw-Hill.

18. US Department of Agriculture, National Institute of Food and Agriculture (2015) Extension. http://nifa.usda.gov/ extension (accessed April 2016)

19. US Department of Agriculture, National Institute of Food and Agriculture (2015) The Expanded Food and Nutrition Education Program Policies. http://nifa.usda.gov/sites/ default/files/program/EFNEP\%20Policy\%20Document\% 202015\%20Update\%20P1.pdf (accessed April 2016).

20. US Department of Agriculture, Food and Nutrition Service (2015) Supplemental Nutrition Assistance Program Education Guidance. Nutrition Education and Obesity Prevention Grant Program. http://snap.nal.usda.gov/snap/Guidance/ FinalFY2016SNAP-EdGuidance.pdf (accessed April 2016).

21. Brim OG, Ryff CD \& Kessler RC (2004) The MIDUS national survey: an overview. In How Healthy Are We?: A National Study of Well-Being at Midlife, pp. 1-36 [OG Brim, CD Ryff and RC Kessler, editors]. Chicago, IL: University of Chicago Press.
22. Lu AH (2012) An incremental shift to the ecological approach of obesity prevention: Extension nutrition managers' use of environmental strategies. PhD Thesis, Cornell University.

23. Ferris GR, Treadway DC, Kolondinsky RW et al. (2005) Development and validation of the Political Skill Inventory. J Manage 31, 126-152.

24. Ajzen I (1991) The theory of planned behaviour. Organ Behav Hum Decis Process 50, 179-211.

25. Harding KE, Porter J, Horne-Thompson A et al. (2004) Not enough time or a low priority? Barriers to evidence-based practice for allied health clinicians. J Contin Educ Health Prof 34, 224-231.

26. Devine CM, Jastran M \& Bisogni CA (2004) On the front line: practice satisfactions and challenges experienced by dietetics and nutrition professionals working in community settings in New York State. J Am Diet Assoc 104, 787-792.

27. US Department of Agriculture, Extension Service (1983) Expanded Food and Nutrition Education Program Policies. Washington, DC: US Department of Agriculture, Extension Service.

28. US Congress (2010) Healthy, Hunger-Free Kids Act of 2010. Public Law 111-296. http://www.gpo.gov/fdsys/pkg/ PLAW-111publ296/pdf/PLAW-111publ296.pdf (accessed April 2016).

29. US Department of Agriculture, Food and Nutrition Services (2009) Supplemental Nutrition Assistance Program Education (SNAP-Ed) Plan Guidance, 2009. https://www.cdph.ca.gov/ programs/cpns/Documents/Network-SNAP-EdGuidance2009-01.pdf (accessed April 2016).

30. US Department of Agriculture \& US Department of Health and Human Services (2010) Dietary Guidelines for Americans 2010, 7th ed. Washington, DC: US Government Printing Office; available at http://www.cnpp.usda.gov/ sites/default/files/dietary_guidelines_for_americans/PolicyDoc.pdf

31. Byham-Gray LD, Gilbride JA, Dixon LB et al. (2005) Evidence-based practice: what are dietitians' perceptions, attitudes, and knowledge? J Am Diet Assoc 105, 1574-1581. 